\title{
Prevalence and incidence of cognitive impairment in an elder Portuguese population $(65-85$ years old)
}

\author{
Ricardo Pais ${ }^{1,2,3^{*}}$ (D), Luís Ruano ${ }^{1,2,4}$, Carla Moreira ${ }^{1,2}$, Ofélia P. Carvalho ${ }^{1,2}$ and Henrique Barros ${ }^{1,2}$
}

\begin{abstract}
Background: The increase in average life expectancy increases the risk of illness and frailty in the elderly, especially in the cognitive arena. This study has the objective to estimate the prevalence and incidence of cognitive impairment, in a representative sample of 65 to 85 years old followed for a mean period of 6-years.

Methods: Subjects aged 65-85 years $(n=586)$ were screened at baseline (1999-2004) to estimate the prevalence of cognitive impairment using the Mini-Mental State Examination. A total of 287 individuals with a normal MMSE at baseline were reassessed after 6.2 mean years ( \pm 4.30 years) to evaluate the incidence of cognitive impairment, defined as scoring below the age and education-adjusted MMSE cut-off points adapted for the Portuguese population. We did not exclude Dementia.

Results: The baseline prevalence of cognitive impairment was 15.5\% (95\% Cl: 12.7-18.7). Higher in women (18.9\%; 95\% Cl: 14.9-23.3), that in men (10.4\%; 95\% Cl: 6.7-15.1). Increased with age and was highest for participants without any schooling. The overall incidence rate was 26.97 per 1000 person-years; higher in women (33.8 per 1000 person-years) than in men (18.0 per 1000 person-years). Higher for the oldest participants and those with no schooling. Taking the standard European population, we estimated a prevalence of $16.5 \%$ and an incidence of 34.4 per 1000 person-years.

Conclusion: The prevalence of cognitive impairment in Portugal is within the estimated interval for the European population, and the incidence is lower than for the majority of the European countries. Women, senior and elders without education have a higher risk of cognitive impairment. In our sample, neither employment nor marital status has a significant effect on cognitive impairment.
\end{abstract}

Keywords: Cognitive impairment, Prevalence, Incidence, Population-based cohort, EPIPorto

\section{Background}

The ageing of the world population is a demographic trend that will intensify in the coming decades. Eurostat projects that by 2050 Portugal will be the European country with the highest percentage of people aged 55 years or more

\footnotetext{
* Correspondence: pais.ricardo@gmail.com

'EPIUnit - Instituto de Saúde Pública, Universidade do Porto, Rua das Taipas, $n^{\circ} 135,4050-600$ Porto, Portugal

2Departamento de Epidemiologia Clínica, Medicina Preditiva e Saúde Pública, Faculdade de Medicina da Universidade do Porto, Alameda Prof. Hernâni Monteiro, 4200-319 Porto, Portugal

Full list of author information is available at the end of the article
}

(47\%) [1]. The growing number of older people poses health challenges such as increasing the prevalence of disease and disability in the elders, especially the burden of cognitive dysfunctions [2]. Cognitive impairment increases the risk of dementia and mortality in the elders $[3,4]$. It is characterised by individuals having more difficulties with memory, learning, and the ability to focus on a task, than would be normally expected for the individual's age and educational level [5]. It ranges from mild deficits that are not clinically detectable to dementia [5]. It has a social impact and is associated with other pathologies, such as

C C The Author(s). 2020 Open Access This article is licensed under a Creative Commons Attribution 4.0 International License, which permits use, sharing, adaptation, distribution and reproduction in any medium or format, as long as you give appropriate credit to the original author(s) and the source, provide a link to the Creative Commons licence, and indicate if changes were made. The images or other third party material in this article are included in the article's Creative Commons licence, unless indicated otherwise in a credit line to the material. If material is not included in the article's Creative Commons licence and your intended use is not permitted by statutory regulation or exceeds the permitted use, you will need to obtain permission directly from the copyright holder. To view a copy of this licence, visit http://creativecommons.org/licenses/by/4.0/. The Creative Commons Public Domain Dedication waiver (http://creativecommons.org/publicdomain/zero/1.0/) applies to the data made available in this article, unless otherwise stated in a credit line to the data. 
Alzheimer or Dementia [6, 7]. Age, sex and level of education are considered risk factors for cognitive impairment [4]. Continued professional activities may be protective against cognitive decline [8] however there is a lack of information about the impact on cognitive function of postponement of retirement age. Also, changing demographics characteristics added to a higher divorce rate increases the number of older people living alone, especially women, which traditionally already presented with an increased risk of cognitive decline $[1,9,10]$.

Reports on the prevalence and incidence of cognitive impairment, as well as its relation with comorbidities and sociodemographic factors, are essential for public health and clinical care policy. They are necessary to allow primary and secondary prevention measures within the healthcare system.

In Europe, published studies report the prevalence of cognitive impairment to be between 5.1 and 24.5\% [1116], whereas in North America, the estimated cognitive impairment prevalence ranges from 13.8 to $28.3 \%$ [1719]. In Europe reports that used the Mini-Mental State Exam for cognitive impairment evaluation in samples with the same age characteristics as ours estimated cognitive impairment prevalence between 7.7 and 33.1\% $[12,16,20]$. The incidence of cognitive impairment ranges from 56.5 to 76.8 per 1000 person-years in Europe $[16,20,21]$ and from 41.8 to 65.4 per 1000 personyears, in North America [22-24] In Portugal, previously published studies report a prevalence of cognitive impairment ranging from 9.3 to $12.0 \%[10,25,26]$ and as far as we know, the incidence is unknown.

\section{Methods}

Aim

This study aims to estimate the prevalence and incidence of cognitive impairment after 6.2 mean year's follow-up assessed using the Mini-Mental State Exam (MMSE) in a cohort of city dwellers from Porto, Portugal, aged 65 to 85 years old, and to evaluate the impact of age, sex, schooling, retirement and civil status in cognitive function. For the main variables of interest, we hypothesize that cognitive impairment prevalence and incidence are similar to other European countries.

\section{Study population}

The EPIPorto cohort study design and methodology have been published previously [27, 28]. In brief, between 1999 and 2004, we assembled a representative sample of community dwellers of Porto, an urban centre in the northwest of Portugal, with approximately 300, 000 inhabitants at the time. We selected Households by random digit dialling of landline telephones. Within each household, selected by simple random sampling a permanent resident aged 18 years or more and not replaced refusals. The proportion of participation was $70 \%$, and the final sample size was 2485 individuals. Of the 633 participants with age between 65 and 85 years old, 586 completed the assessment at baseline. The follow-up evaluation took place in two waves, part of the participants $(N=221)$ were evaluated during the first follow-up, between 2005 and 2008, and the others were evaluated only on the second follow-up $(N=66)$, between 2013 and 2015 (Fig. 1).

\section{Data collection and definition of variables}

Trained interviewers performed a face-to-face questionnaire which collected data on sociodemographic and behavioural characteristics [29] and administered the MiniMental State Exam (MMSE) at the beginning of each interview [30]. Education was recorded as completed years of schooling and further categorized into three groups: zero years, one to 9 years and more than 10 years of schooling. Civil status was categorized in two groups: married or living together, and not-married (divorced, single or widowed). Professional status was considered to be either working (participants employed), retired (considering retirement as a direct transition between a situation of full employment and a situation where the individual is entirely inactive and where most of his resources consist of pension benefits), or housewives. There were no unemployed participants. Cognitive impairment was evaluated using the MMSE [30], with cut-off points adjusted by years of schooling validated for the Portuguese population: 22 for $0-2$ years; 24 for 3-6 years and 27 for seven or more years of schooling [31]. Subjects with an MMSE score below the age and education adjusted cut-off point were considered to have cognitive impairment. The MMSE is the most cited small-sized scale used for dementia and cognitive impairment assessment and is thought to be a reliable and valid test for cognitive impairment [30, 32].

\section{Prevalence evaluation}

At the baseline evaluation, 633 participants were aged 65 to 85 years old, but we excluded 47 subjects due to missing information on the Mini-Mental State Exam (MMSE). The final sub-sample was 586 participants (Table 1) with 71.95 years $( \pm 4.84 \mathrm{SD})$ mean age; 355 were women (60.6\%); 57 (9.7\%) had no education, 432 (73.7\%) had one to 9 years of education, and 97 (16.6\%) had more than 10 years (16.6\%) of schooling; 350 (59.7\%) were married or living in civil union; 464 (79.2) were retired.

\section{Incidence evaluation}

There were two follow-up evaluations where the participants completed a questionnaire and had a physical examination. The first follow-up was between 2005 and 


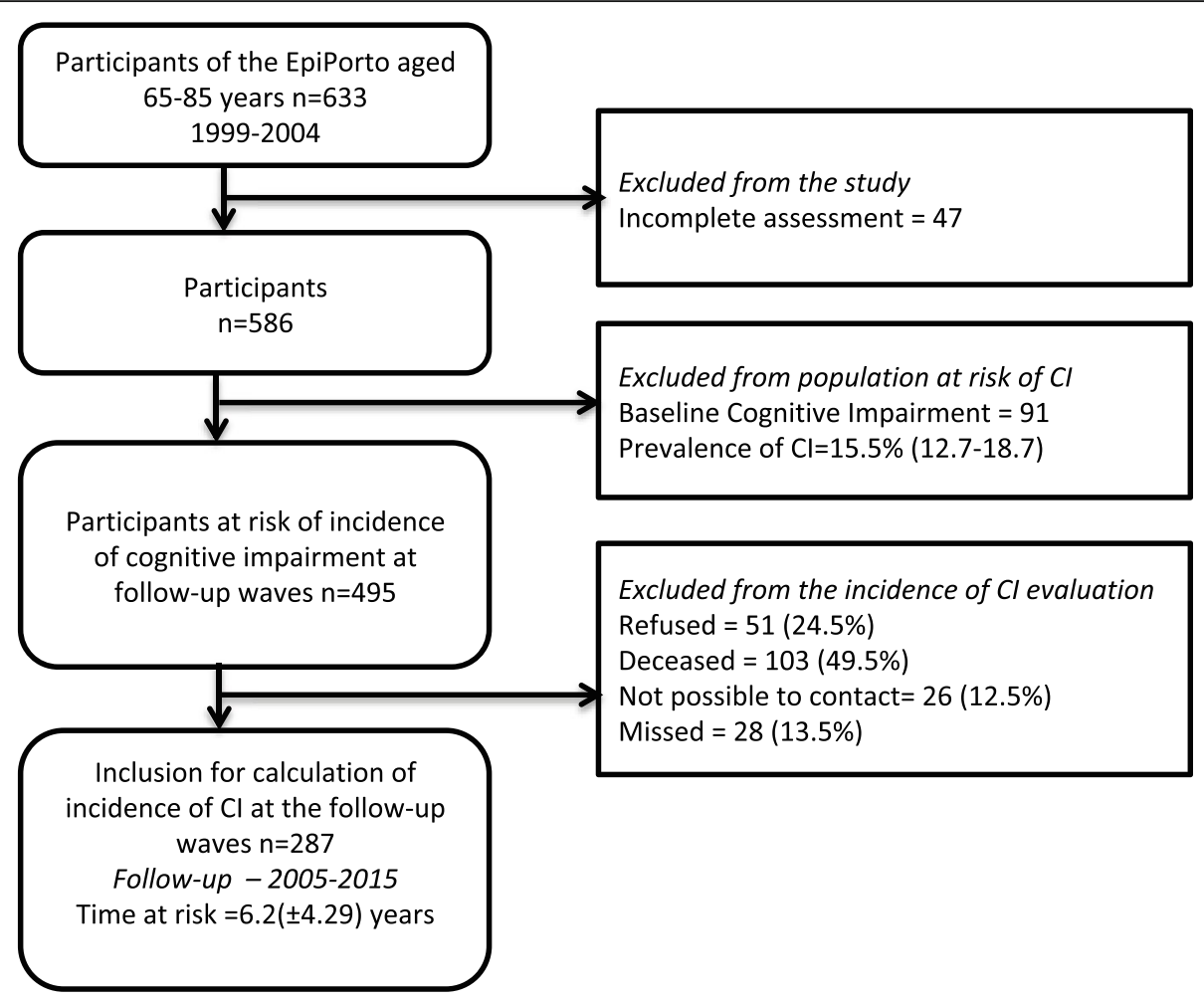

Fig. 1 Flow-chart of participants through the steps of the study and final results on the frequency of cognitive impairment

Table 1 Socio-demographic characteristics of participants

\begin{tabular}{|c|c|c|c|c|}
\hline Characteristic & Baseline & Follow-up & Lost to follow-up & $P$ value \\
\hline N & 586 & 287 & 208 & \\
\hline \multicolumn{5}{|l|}{ Sex } \\
\hline Female & $355(60.6)$ & $169(58.9)$ & $119(57.2)$ & \multirow[t]{2}{*}{0.709} \\
\hline Male & $231(39.4)$ & $118(41.1)$ & $89(42.8)$ & \\
\hline \multicolumn{5}{|l|}{ Age (years) } \\
\hline [65-69] & $216(36.9)$ & $125(43.6)$ & $67(32.2)$ & \multirow[t]{4}{*}{$0.010^{*}$} \\
\hline [70-74] & $200(34.1)$ & $100(34.8)$ & $70(33.7)$ & \\
\hline [75-79] & $120(20.5)$ & $46(16.0)$ & $50(24.0)$ & \\
\hline [80-85] & $50(8.5)$ & $16(5.6)$ & $21(10.1)$ & \\
\hline \multicolumn{5}{|l|}{ Education } \\
\hline 0 & $57(9.7)$ & $17(5.9)$ & $14(6.7)$ & \multirow[t]{3}{*}{0.751} \\
\hline [1-9] & $432(73.7)$ & $219(76.3)$ & $162(77.9)$ & \\
\hline$\geq 10$ & 97 (16.6) & $51(17.8)$ & $32(15.4)$ & \\
\hline \multicolumn{5}{|l|}{ Marital Status } \\
\hline Married/Civil Union & $350(59.7)$ & $180(62.7)$ & $118(56.7)$ & \multirow[t]{2}{*}{0.179} \\
\hline Single, divorced, widower & $236(40.3)$ & $107(37.3)$ & $90(43.3)$ & \\
\hline \multicolumn{5}{|l|}{ Employment Status } \\
\hline Work & $50(8.5)$ & $26(9.1)$ & $18(8.7)$ & \multirow[t]{3}{*}{0.626} \\
\hline Retired & $464(79.2)$ & $233(81.2)$ & $164(78.8)$ & \\
\hline Housewives & $71(12.1)$ & $28(9.8)$ & $26(12.5)$ & \\
\hline
\end{tabular}

Legend: Data are $n(\%) ; P$-value compares follow-up to lost to follow up, obtained with Chi-square test

*Significant at $p<0.05$ 
2008 and the second follow-up between 2013 and 2015 . Some participants were evaluated only during the 1st or the 2nd follow-up. Of the initial 586 eligible participants, there were overall 208 losses with 103 (49.5\%) deaths, 51 (24.5\%) refusals, 26 (12.5\%) were not possible to contact and 28 (13.5\%) missed without justification. We reevaluated a total of 287 participants (mean follow-up of 6.2 years, SD 4.30 years). There were no significant differences regarding sex, education, civil status or employment status between follow up participants and those lost to follow-up (Table 1). However, participants lost to follow-up were older (72.58 vs 71.09 mean age in years).

\section{Competing risk model}

During the follow-up, in the disease/death process, often more than one type of event plays a role. We are interested as the first event a diagnosis of cognitive impairment. However, death may prevent the event of interest from occurring, because the person died before the diagnosis of cognitive impairment. Therefore, death is a competing risk of cognitive impairment and may substantially change the risk of disease diagnosis. Death substantially reduces the probability of being diagnosed with cognitive impairment, and hence is treated as a competing risk event when calculating cognitive impairment incidence [33, 34]. Ignoring death as a competing risk or treat it as no informative censored observations will lead to a bias in the standard methods for estimate the probability of the event [35] such as the KaplanMeier estimate [36]. The assumption of independence of the time to event and the censoring distributions is violated and then violates one of the fundamental assumptions of the Kaplan-Meier estimator. We considered the time of event as the time from entering in the cohort to the first event, cognitive impairment or death, during the follow-up.

The cumulative incidence function (CIF) allows for estimation of the incidence of the occurrence of an event while taking competing risk into account [37, 38]. This allows one to estimate incidence in a population where all competing events must be accounted for in clinical decision making. It denotes the probability of experiencing the $k$ th event before time $\mathrm{t}$ and before the occurrence of a different type of event, i.e., for instance, the probability of experience death before 70 years old, before the occurrence of the cognitive impairment. The CIF has the desirable property that the sum of the CIF estimates of the incidence of each of the individual outcomes will equal the CIF estimates of the incidence of the composite outcome consisting of all of the competing events [39].

We performed the competing risks analysis to the 495 participants at risk of incidence of cognitive impairment, excluding those 105 that refused to participate, missed or were impossible to contact along all period of the follow-up. From these 390, 103 died before cognitive impairment diagnosis, 48 were diagnosed with cognitive impairment and 239 were still alive without cognitive impairment diagnosis.

\section{Statistical analysis}

We assessed differences in the prepositions using the Chi-Square test. Losses to follow-up were compared to participants in the follow-up using the Chi-Square test. Calculated crude incident rates dividing the number of events by total number of person-years at risk. Counted time at risk as the time in years between the baseline evaluation and the last follow-up that each participant attended and taking into consideration the full length of time for subjects who remained free of cognitive impairment, and estimate time of onset of cognitive impairment being set to the midpoint between the baseline and follow-up observation waves for those participants who did develop the disease. Poisson generalized linear models were used to determine confidence intervals, with Log of time at risk as to the offset. We tested the possible interaction of each explanatory variable with age, sex, education and retirement status was tested. Sex-, age-, education- and education- adjusted OR and RR were estimated. Standardized prevalent and incident rates were calculated for the Portuguese population using data from the last census, in 2011 [40], and for European population using data from the standard European population, 2013 [41]. The CIFs were estimated in $\mathrm{R}$ using the cuminc function in the cmprsk $\mathrm{R}$ [42] package which uses the cumulative incidence function introduced by Kalbfleisch and Prentice [38].We used the Gray's test [43] for equality of CIFs across groups. We assessed differences in the MMSE mean score reduction of participants with and without cognitive impairment with T-test for independent samples. The remaining statistical analyses were performed using $\mathrm{SPSS}^{\circ}$ version 21. We include the Box Plot of the Mini-Mental State Examination score of the population at baseline evaluation and of the participants with or without cognitive impairment at the follow-up evaluation as Supplementary material (Figure S1).

\section{Results}

\section{Prevalence evaluation}

The crude prevalence of cognitive impairment was 15.5\% (95\% CI: 12.7-18.7) at baseline. The standardized prevalence rate for the Portuguese population was $16.9 \%$ and for the standard European population was 16.5\%. Prevalence was lower in men (10.4\%; 95\% CI: 6.7-15.1) than in women $(18.9 ; 95 \%$ CI: 14.9-23.3), with the odds of presenting cognitive impairment, adjusted for age and education, of 0.95 (95\% CI: 0.89-1.01). 
The prevalence of cognitive impairment increases with age, being higher at $80-85$ years than $65-69$ years (26.0; 95\% CI: $17.3-40.2$ vs 11.1 ; 95\% CI: 9.3-17.2), with the odds for cognitive impairment, adjusted for sex and education, being 1.14 higher.

The cognitive impairment prevalence is higher for participants with zero years of schooling $(45.6$; 95\% CI: 32.4-59.3) and slightly higher for participants with more than 10 years than for participants with one to 9 years (14.4; 95\% CI 8.1-23.0 vs 11.8 ; 95\% CI 8.9-15.2) with statistically significant differences.

Not-married participants had a higher prevalence of cognitive impairment (16.5; 95\% CI: $12.0-21.9$ vs 14.9 ; 95\% CI: 11.3-19.0), but the difference was not statistically significant after adjustment for age and education.

Retired participants had a higher prevalence of cognitive impairment than the working participants (14.4; 95\% CI: 11.4-18.0 vs 12.0 ; 95\% CI: 4.6-24.3) and housewives have the highest prevalence $(23.9 ; 95 \% \mathrm{CI}: 14.6-35.5)$ but without statistically significant differences. (Table 2 ).

\section{Incidence evaluation}

During the study protocol, 48 individuals developed cognitive impairment, an incidence rate of 26.97 per 1000 person-years (95\% CI: 20.3-35.8). The standardized incidence rate using the Portuguese population was 35.7 per 1000 person-years and using the standard European population was 34.4 per 1000 person-years.

The incidence of cognitive impairment was higher in women (33.8 per 1000 person-years; 95\% CI: 24.2-47.4) than men (18.0 per 1000 person-years; $95 \%$ CI: $10.7-30.5)$ and increasing with age at $80-85$ years old (66.0 per 1000 person-years; 95\% CI: 27.5-158.7) vs 65-69 years old (21.1 per 1000 person-years; 95\% CI: 13.5-33.1).

As observed on baseline prevalence, the incidence is higher for participants with zero years of schooling (126.4; 95\% CI: 68.0-234.8) and almost the same for participants with 1 to 9 years and more than 10 years (21.6; 95\% CI: $15.0-31.0$ vs 25.3 ; 95\% CI $13.2-48.7$ ).

Not married participants have a higher incidence rate of cognitive impairment (32.5; 95\% CI: 21.4-49.4 vs 23.6; 95\% CI: 16.1-34.6), but the difference did not reveal statistically significant differences after adjusting for age and education.

Retired participants have a higher incidence of cognitive impairment than working participants (30.0; 95\% CI: 21.3-37.9 vs 18.1 ; 95\% CI: $6.8-48.3$ ) but without statistically significant differences. (Table 3 ).

Table 2 Observed prevalence of cognitive impairment by socio-demographic characteristics

\begin{tabular}{|c|c|c|c|c|}
\hline Characteristics & $\mathrm{n}$ & Prev. \% (95\% Cl) & $p$-value & OR (95\% CI) Adjusted \\
\hline \multicolumn{5}{|l|}{ Sex } \\
\hline Female & 67 & $18.9(14.9-23.3)$ & $0.006^{*}$ & 1 [reference] $^{\mathrm{a}}$ \\
\hline Male & 24 & $10.4(6.7-15.1)$ & & $0.95(0.89-1.01)$ \\
\hline \multicolumn{5}{|l|}{ Age (years) } \\
\hline [65-69] & 24 & $11.1(9.3-17.2)$ & $0.026^{*}$ & 1 [reference] $^{\mathrm{b}}$ \\
\hline$[70-74]$ & 30 & $15.0(11.0-21.1)$ & & $1.03(0.97-1.10)$ \\
\hline [75-79] & 24 & $20.0(13.3-28.3)$ & & $1.10(1.02-1.19)$ \\
\hline [80-85] & 13 & $26.0(17.3-40.2)$ & & $1.14(1.03-1.27)$ \\
\hline \multicolumn{5}{|l|}{ Education } \\
\hline 0 & 26 & $45.6(32.4-59.3)$ & $0.000^{*}$ & 1 [reference] $^{c}$ \\
\hline [1-9] & 51 & $11.8(8.9-15.2)$ & & $0.72(0.66-0.80)$ \\
\hline$\geq 10$ & 14 & $14.4(8.1-23.0)$ & & $0.74(0.67-0.84)$ \\
\hline \multicolumn{5}{|l|}{ Marital Status } \\
\hline Married/Civil Union & 52 & $14.9(11.3-19.0)$ & 0.584 & 1 [reference] $^{d}$ \\
\hline Single, divorced, widower & 39 & 16.5 (12.0-21.9) & & $0.96(0.90-1.02)$ \\
\hline \multicolumn{5}{|l|}{ Employment Status } \\
\hline Work & 6 & $12.0(4.6-24.3)$ & 0.471 & 1 [reference] $^{\mathrm{a}}$ \\
\hline Retired & 67 & $14.4(11.4-18.0)$ & & $99.6(0.90-1.10)$ \\
\hline Housewives & 17 & $23.9(14.6-35.5)$ & & $1.07(0.94-1.22)$ \\
\hline
\end{tabular}

Legend: Prev Prevalence, OR odds ratio. 95\% Cl: 95\% confidence interval

adjusted for age and education

badjusted for sex and education

cadjusted for sex and age

dadjusted for sex, age and education

* Significant at $p<0.05$ 
Table 3 Observed incidence of cognitive impairment by socio-demographic characteristics

\begin{tabular}{|c|c|c|c|c|}
\hline Characteristics & $\mathbf{n}$ & Incidence $(95 \% \mathrm{Cl})$ per 1000 person-years & $p$-value & RR $(95 \% \mathrm{Cl})$ Adjusted \\
\hline \multicolumn{5}{|l|}{ Sex } \\
\hline Female & 34 & $33.8(24.2-47.4)$ & 0.084 & 1 [reference] $^{a}$ \\
\hline Male & 14 & $18.0(10.7-30.5)$ & & $0.66(0.35-1.27)$ \\
\hline \multicolumn{5}{|l|}{ Age (years) } \\
\hline [65-69] & 19 & $21.1(13.5-33.1)$ & 0.142 & 1 [reference] $^{\mathrm{b}}$ \\
\hline$[70-74]$ & 16 & $25.8(15.8-42.2)$ & & $1.29(0.66-2.52)$ \\
\hline [75-79] & 8 & $43.5(21.7-86.9)$ & & $2.20(0.96-5.05)$ \\
\hline [80-85] & 5 & $66.0(27.5-158.7)$ & & $2.01(0.72-5.58)$ \\
\hline \multicolumn{5}{|l|}{ Education } \\
\hline 0 & 10 & $126.4(68.0-234.8)$ & $0.005^{*}$ & 1 [reference] $^{c}$ \\
\hline [1-9] & 29 & $21.6(15.0-31.0)$ & & $0.21(0.10-0.47)$ \\
\hline$\geq 10$ & 9 & $25.3(13.2-48.7)$ & & $0.25(0.10-0.65)$ \\
\hline \multicolumn{5}{|l|}{ Marital Status } \\
\hline Married/Civil Union & 26 & $23.6(16.1-34.6)$ & 0.296 & 1 [reference] $^{\mathrm{d}}$ \\
\hline Single, divorced, widower & 22 & $32.5(21.4-49.4)$ & & $1.03(0.55-1.93)$ \\
\hline \multicolumn{5}{|l|}{ Employment Status } \\
\hline Work & 4 & $18.1(6.8-48.3)$ & 0.911 & 1 [reference] $^{a}$ \\
\hline Retired & 40 & $30.0(21.3-37.9)$ & & $1.30(0.44-3.79)$ \\
\hline Housewives & 4 & $22.3(24.2-47.4)$ & & $0.79(0.19-3.31)$ \\
\hline
\end{tabular}

Legend: $R R$ relative risk. $95 \%, C l 95 \%$ confidence interval

adjusted for age and education

badjusted for education and sex

cadjusted for age and sex

dadjusted for sex, age and education

*Significant at $p<0.05$

The crude cumulative incidences of cognitive impairment and death in the overall sample are described in Fig. 2, along with the incidence of the composite outcome of all-cause of failure (death or cognitive impairment). The cumulative incidence of all-cause failure is equal to the sum of the cumulative incidences of the 2 cause-specific failures. Although the cumulative incidence of death before the cognitive impairment exceeded that of cognitive impairment diagnosis at each point in time, the incidence of cognitive impairment was not negligible in this population. In the group analysis by sex, the cumulative incidence curves for women and men were statistically different for cognitive impairment before death ( $P$-value 0.0008$)$, and for death before $\operatorname{cog}$ nitive impairment ( $P$-value 0.0004$)$. The estimated CIFs for each cause of failure by sex displayed in Fig. 3 presented notable differences. In women, from 73 years old to 80 years old, the cumulative incidence of cognitive impairment is higher that its competitive event, while for the men, the incidence of death before cognitive impairment is higher in all points in time when compared to the cognitive impairment diagnosis, following the same trend as when analysing the whole sample. The estimates of death before cognitive impairment diagnosis

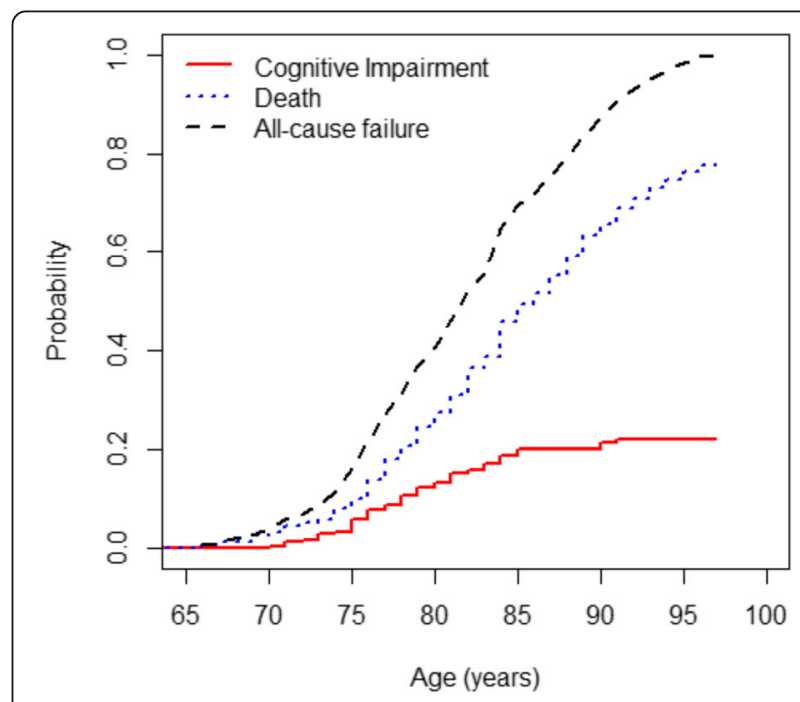

Fig. 2 Cumulative incidence functions. The solid line shows the cumulative incidence of cognitive impairment. The dotted line shows the competing risk event, i.e. death occurring prior to the cognitive impairment. The dashed line shows the cumulative incidence function of all-cause failure, i.e. the sum of the cumulative incidences of the 2 cause-specific failures 

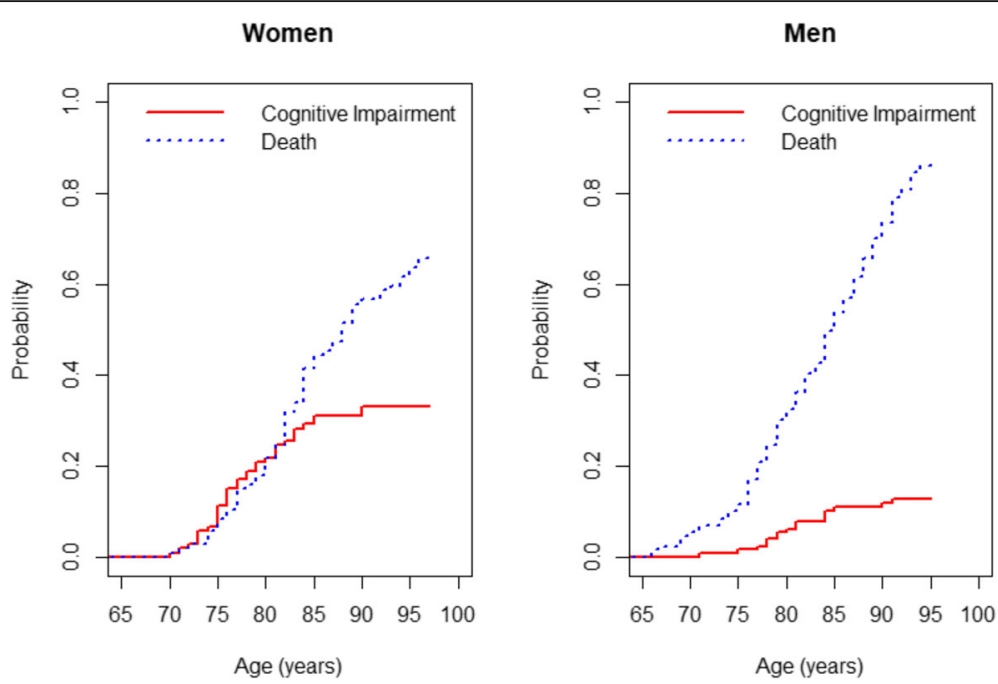

Fig. 3 Cumulative incidence functions by sex. Left panel: The solid line shows the cumulative incidence of cognitive impairment, for women. Right panel: The dotted line shows the competing risk event, i.e. death occurring prior to the cognitive impairment, for Men

of the women exceeds the estimates of cognitive impairment diagnosis in the point's time after 80 years old. The slope of the curves are quite similar in women and men until 70 years -75 years old, however, in the men it can be observed a higher probability of death before cognitive impairment than in the women.

Participants with cognitive impairment had an average MMSE score reduction of 5.33 (SD 3.64), while participants without cognitive impairment had an average of 0.44 reduction $(\mathrm{SD}=1.84)(p=0.000)$ over the time at risk of 6.2 mean years $( \pm 4.30$ years).

\section{Discussion}

In this urban population with 65 to 85 years, the prevalence of cognitive impairment was $15.5 \%$. It was higher in women, in not-married participants, and retired participants, it increased with age and decreased with education years.

Previous studies with Portuguese population samples reported a prevalence of cognitive impairment between 9.3 and $12.0 \%[10,25,26]$ using younger participants, over 50 years old on the first study and over 55 years old on the other two. Both the studies which used the MMSE as a screening test, Nunes et al. [25] and Ruano et al. [26] complemented the results with a neurologist evaluation. It is worth to point out that Ruano et al. [26] report the 2015 prevalence for the EpiPorto cohort with the present study focusing on the period from 1999 to 2004 and that only in the current study was the incidence of cognitive impairment in this population ascertained (1999-2015).

The prevalence estimate found in our study is within the estimated interval for the European population using ascertainment approaches similar to ours $[9,20]$.
As previously reported cognitive impairment prevalence was higher in women than in men $[9,10,44]$, with studies pointing out hormonal causes, namely the loss of estrogens in women, to justify this difference [45]. It increased in frequency with increasing age between the ages of 65 and 85 years, which is in accordance to other studies that associated ageing with cognitive decline and dementia [9, $10,44,46]$ and it is associated with low levels of education, possibly due to the higher cognitive reserve of the ones with more years of education $[9,44,47]$. Participants without schooling have a higher prevalence of cognitive impairment than participants with at least some schooling. Participants with more than 10 years of schooling have a higher prevalence of cognitive impairment compared with those between one and 9 years of schooling. However, this may be attributable to their higher mean age and presence of more participants with $80-85$ years old (13.4\% vs $6.9 \%$ ). When we determined the odds ratio, adjusted for sex and age, the risk is almost the same (0.72 vs 0.74$)$ between both groups and statistically different for the group without any schooling. It was also slightly higher for notmarried participants $[9,44,48]$ despite not reaching statistical significance and we did not find differences between retired and non-retired participants (Table 2).

For 6.2 mean years of follow-up time, we observed that the incidence rate of cognitive impairment was 26.97 per 1000 person-years. The standardized incident rate for the Portuguese population was 35.7 and for the standard European population was 34.4 per 1000 person-years. The cognitive impairment incidence we found in our sample is lower than estimates for other European countries [20, 21, 49] and North America, [22, 23] however this might be due to the older populations and different cognitive impairment definitions used in these studies. 
In concordance with other studies [22, 24, 49, 50], we also observed a trend towards increased incidence with older age, and higher in women albeit without reaching statistical significance. These findings were also achieved when considering death as a competing risk of cognitive impairment.

Participants with zero years of schooling have a higher incidence of cognitive impairment than the ones with schooling, which is in concordance to the impact of education years reported in previous findings [20,51].

Non-married participants have a non-significant trend towards a higher incidence of cognitive impairment, which could be explained by the memory and cognition stimulation of the married participants [52].. For employment status, we observe that retired participants have a trend towards a higher incidence of cognitive impairment than the ones which are still working, after adjusting for age and education, which may indicate a protective effect of working, as described before $[8,53]$. It would be interesting to conduct further work to try to determine if indeed working has a protective effect on cognitive decline or if other social dimensions involved in being employed mediates this effect.

The average MMSE score reduction is higher in participants with cognitive impairment compared with other participants, which demonstrates a more pronounced cognitive loss on the first ones that must be taken into account when defining preventive measures in the Health System.

A previous study [26] has found that one of the major causes of cognitive impairment in this population stems from vascular disease, as such we suggest that help managing blood pressure and an increase in physical activity, if targeted to these groups, could lead to significant public health improvements.

In Portugal, in the period under analysis, from 1999 to 2015, the demographic characteristics of the population over 65 years old changed and, according to PORDATA, the percentage of older people increased from 15.9 to $20.5 \%$ [54], and the number of people without education decreased by $36.7 \%$ and those with higher education, increased by $247.7 \%$ [55]. The increased education may have contributed to the decrease in the prevalence of cognitive impairment from 15.5 to $9.3 \%$ [26], despite some methodological differences in the two studies in the EpiPorto cohort discussed above. The increase in schooling will mitigate the effect of increasing average life expectancy, but it should be taken other measures because by 2050, Portugal will be one of the European countries with a higher percentage of older people and with the highest old-age dependency ratio.

The main strengths of our study are the populationbased cohort and the long-term prospective study design as well as the use of MMSE published cut-off points adjusted for education. This study provides an estimate of the prevalence and incidence of cognitive impairment in an elder western European cohort providing essential data to target public health strategies accurately.

Some methodological limitations may have overestimated the results, namely the inability to diagnose dementia, meaning that we could not exclude participants with dementia from the study, which may have overestimated the prevalence of cognitive impairment at baseline. Mortality as a competing risk may have overestimated the incidence of cognitive impairment. Participants lost-to-follow-up where older and with lower mean MMSE scores than the participants and this could have underestimated the incidence calculations.

\section{Conclusion}

This study reports a prevalence of cognitive impairment of $15.5 \%$ and an incidence of 26.97 per 1000 personyears in a cohort of city dwellers from Porto, Portugal, aged 65 to 85 years old. Women and elders without schooling have a higher risk of developing cognitive impairment, and this risk increases with ageing. This study highlights the need to develop preventive health measures targeted to these groups to help maintain brain health with ageing. In our study we found that neither retirement nor marital status have a significant effect on cognitive impairment.

\section{Supplementary Information}

The online version contains supplementary material available at https://doi. org/10.1186/s12877-020-01863-7.

Additional file 1: Figure S1. Box Plot of the Mini-Mental State Examination score of the population at baseline evaluation and participants with or without cognitive impairment at the follow-up evaluation.

\section{Abbreviations \\ MMSE: Mini-Mental State Examination; CIF: Cumulative incidence function; OR: Odds ratio; RR: Relative Risk}

\section{Acknowledgements}

Not applicable.

\section{Authors' contributions}

All authors contributed to the study conception and design. Material preparation and data collection: RP. Statistical analysis: RP, CM. Writing review and editing: $R P, L R, C M, O C, H B$. Supervision: $H B$. RP wrote the first draft of the manuscript and all authors commented on previous versions of the manuscript. All authors read and approved the final manuscript.

\section{Funding}

Fundo Europeu de Desenvolvimento Regional (FEDER), and the Programa Operacional Competitividade e Internacionalização (POCI) (POCl-01-0145FEDER-016867) of the European Union, and by the Fundação para a Ciência e a Tecnologia, no âmbito da Unidade de Investigação em Epidemiologia Instituto de Saúde Pública da Universidade do Porto (EPIUnit) (POCl-01-0145FEDER-006862; Ref. ${ }^{\circ}$ FCT UID/DTP/04750/2013). The role of funding body was to funding EpiPorto Cohort Study. 


\section{Availability of data and materials}

The datasets used and analysed during the current study are available from the corresponding author on reasonable request.

\section{Ethics approval and consent to participate}

All procedures performed in studies involving human participants were in agreement with the ethical standards of the institutional and national research committee and with the 1964 Helsinki declaration and its later amendments or comparable ethical standards. The ethics committee of Hospital de São João approved the study. All individual participants received an explanation on the purpose and design of the study and gave their written informed consent in the evaluation. In participants with cognitive impairment, written consent was also sought from a valid surrogate.

\section{Consent for publication}

Not Applicable.

\section{Competing interests}

The authors declare that they have no competing of interest and certify responsibility for the manuscript.

\section{Author details \\ 'EPIUnit - Instituto de Saúde Pública, Universidade do Porto, Rua das Taipas, n 135, 4050-600 Porto, Portugal. ${ }^{2}$ Departamento de Epidemiologia Clínica, Medicina Preditiva e Saúde Pública, Faculdade de Medicina da Universidade do Porto, Alameda Prof. Hernâni Monteiro, 4200-319 Porto, Portugal. ${ }^{3}$ Unidade de Saúde Familiar Lusitana, Av. António José Almeida, 3514-511 Viseu, Portugal. ${ }^{4}$ Departamento de Neurologia, Hospital de São Sebastião, Centro Hospitalar de Entre o Douro e Vouga, Rua Cândido Pinho, 4520-211 Santa Maria da Feira, Portugal.}

\section{Received: 8 July 2020 Accepted: 31 October 2020} Published online: 16 November 2020

\section{References}

1. Eurostat. Ageing Europe Looking at the lives of older people in the EU. Luxembourg: Publications of the European Union; 2019.

2. Crimmins EM, Kim JK, Langa KM, Weir DR. Assessment of cognition using surveys and neuropsychological assessment: the health and retirement study and the aging, demographics, and memory study. J Gerontol B Psychol Sci Soc Sci. 2011;66(Suppl 1):i162-71.

3. Park MH, Kwon DY, Jung JM, Han C, Jo I, Jo SA. Mini-mental status examination as predictors of mortality in the elderly. Acta Psychiatr Scand. 2013;127(4):298-304.

4. Roberts R, Knopman DS. Classification and epidemiology of MCl. Clin Geriatr Med. 2013;29(4):753-72.

5. ICD-10. International Statistical Classification of Diseases and Related Health Problems 10th Revision 2010 [Available from: http://apps.who.int/ classifications/icd10/browse/2010/en\#/F06.7.

6. Geda YE. Mild cognitive impairment in older adults. Curr Psychiatry Rep. 2012;14(4):320-7.

7. Millan-Calenti JC, Tubio J, Pita-Fernandez S, Gonzalez-Abraldes I, Lorenzo T, Maseda A. Prevalence of cognitive impairment: effects of level of education, age, sex and associated factors. Dement Geriatr Cogn Disord. 2009;28(5): $455-60$.

8. Coe NB, von Gaudecker HM, Lindeboom M, Maurer J. The effect of retirement on cognitive functioning. Health Econ. 2012;21 (8):913-27.

9. Rodriguez-Sanchez E, Mora-Simon S, Patino-Alonso MC, Garcia-Garcia R, Escribano-Hernandez A, Garcia-Ortiz L, et al. Prevalence of cognitive impairment in individuals aged over 65 in an urban area: DERIVA study. BMC Neurol. 2011;11:147.

10. Paul C, Ribeiro O, Santos P. Cognitive impairment in old people living in the community. Arch Gerontol Geriatr. 2010;51(2):121-4.

11. De Ronchi D, Berardi D, Menchetti M, Ferrari G, Serretti A, Dalmonte E, et al. Occurrence of cognitive impairment and dementia after the age of 60: a population-based study from northern Italy. Dement Geriatr Cogn Disord. 2005;19(2-3):97-105.

12. Wu YT, Prina AM, Jones AP, Barnes LE, Matthews FE, Brayne C. Community environment, cognitive impairment and dementia in later life: results from the cognitive function and ageing study. Age Ageing. 2015;44(6):1005-11.
13. Zaganas IV, Simos P, Basta M, Kapetanaki S, Panagiotakis S, Koutentaki I, et al. The Cretan aging cohort: cohort description and burden of dementia and mild cognitive impairment. Am J Alzheimers Dis Other Dement. 2019; 34(1):23-33.

14. Freak-Poli R, Licher S, Ryan J, Ikram MA, Tiemeier H. Cognitive impairment, sexual activity and physical tenderness in community-dwelling older adults: a cross-sectional exploration. Gerontology. 2018;64(6):589-602.

15. Lara E, Koyanagi A, Olaya B, Lobo A, Miret M, Tyrovolas S, et al. Mild cognitive impairment in a Spanish representative sample: prevalence and associated factors. Int J Geriatr Psychiatry. 2016;31(8):858-67.

16. Veronese N, Stubbs B, Trevisan C, Bolzetta F, De Rui M, Solmi M, et al. What physical performance measures predict incident cognitive decline among intact older adults? A 4.4year follow up study. Exp Gerontol. 2016;81:110-8.

17. Manly JJ, Bell-McGinty S, Tang MX, Schupf N, Stern Y, Mayeux R. Implementing diagnostic criteria and estimating frequency of mild cognitive impairment in an urban community. Arch Neurol. 2005;62(11):1739-46.

18. Ortiz GG, Arias-Merino ED, Flores-Saiffe ME, Velazquez-Brizuela IE, MaciasIslas MA, Pacheco-Moises FP. Prevalence of cognitive impairment and depression among a population aged over 60 years in the metropolitan area of Guadalajara, Mexico. Curr Gerontol Geriatr Res. 2012;2012:175019.

19. Aliberti MJR, Cenzer IS, Smith AK, Lee SJ, Yaffe K, Covinsky KE. Assessing risk for adverse outcomes in older adults: the need to include both physical frailty and cognition. J Am Geriatr Soc. 2018;67(3):477-83.

20. Ravaglia G, Forti P, Montesi F, Lucicesare A, Pisacane N, Rietti E, et al. Mild cognitive impairment: epidemiology and dementia risk in an elderly Italian population. J Am Geriatr Soc. 2008;56(1):51-8.

21. Luck T, Riedel-Heller SG, Luppa M, Wiese B, Wollny A, Wagner M, et al. Risk factors for incident mild cognitive impairment--results from the German study on ageing, cognition and dementia in primary care patients (AgeCoDe). Acta Psychiatr Scand. 2010;121(4):260-72.

22. Potvin O, Forget $\mathrm{H}$, Grenier S, Preville M, Hudon C. Anxiety, depression, and 1 -year incident cognitive impairment in community-dwelling older adults. J Am Geriatr Soc. 2011;59(8):1421-8.

23. Boyle PA, Buchman AS, Wilson RS, Leurgans SE, Bennett DA. Physical frailty is associated with incident mild cognitive impairment in community-based older persons. J Am Geriatr Soc. 2010;58(2):248-55.

24. Plassman BL, Langa KM, McCammon RJ, Fisher GG, Potter GG, Burke JR, et al. Incidence of dementia and cognitive impairment, not dementia in the United States. Ann Neurol. 2011;70(3):418-26.

25. Nunes B, Silva RD, Cruz VT, Roriz JM, Pais J, Silva MC. Prevalence and pattern of cognitive impairment in rural and urban populations from northern Portugal. BMC Neurol. 2010;10:42.

26. Ruano L, Araujo N, Branco M, Barreto R, Moreira S, Pais R, et al. Prevalence and causes of cognitive impairment and dementia in a population-based cohort from northern Portugal. Am J Alzheimers Dis Other Dement. 2019; 34(1):49-56.

27. Oliveira A, Lopes C, Severo M, Rodriguez-Artalejo F, Barros H. Body fat distribution and C-reactive protein--a principal component analysis. Nutr Metab Cardiovasc Dis. 2011;21(5):347-54.

28. Pereira M, Lunet N, Paulo C, Severo M, Azevedo A, Barros H. Incidence of hypertension in a prospective cohort study of adults from Porto, Portugal. BMC Cardiovasc Disord. 2012;12:114.

29. ISPUP: EpiPorto 2020. https://ispup.up.pt/research/research-structures/?lang= pt. Acessed 27 Jul 2020.

30. Costa D, Severo M, Fraga S, Barros H. Mini-cog and mini-mental state examination: agreement in a cross-sectional study with an elderly sample. Dement Geriatr Cogn Disord. 2012;33(2-3):118-24.

31. Joana Morgado CR, Maruta C, Guerreiro M, Martins I. New normative values of mini-mental state examination. Sinapse. 2009;9:10-6 Publicação da Sociedade Portuguesa de Neurologia.

32. De Marchis GM, Foderaro G, Jemora J, Zanchi F, Altobianchi A, Biglia E, et al. Mild cognitive impairment in medical inpatients: the mini-mental state examination is a promising screening tool. Dement Geriatr Cogn Disord. 2010;29(3):259-64.

33. Putter H, Fiocco M, Geskus RB. Tutorial in biostatistics: competing risks and multi-state models. Stat Med. 2007;26(11):2389-430.

34. Gooley TA, Leisenring W, Crowley J, Storer BE. Estimation of failure probabilities in the presence of competing risks: new representations of old estimators. Stat Med. 1999;18(6):695-706.

35. van Walraven C, Hawken S. Competing risk bias in Kaplan-Meier risk estimates can be corrected. J Clin Epidemiol. 2016;70:101-5. 
36. Kaplan EL MP. Nonparametric estimation from incomplete observations. J Am Stat Assoc. 1958;53:457-81.

37. Marubini EVM. Analysing survival data from clinical trials and observational studies. New York: Wiley; 1995

38. Kalbfleisch JPR. The analysis of failure time data. 2nd ed. New York: Wiley; 2002

39. Austin PC, Lee DS, Fine JP. Introduction to the analysis of survival data in the presence of competing risks. Circulation. 2016;133(6):601-9.

40. OECD. Completed databases. 2015. http://stats.oecd.org/Index. aspx?DatasetCode=POP_FIVE_HIST. Acessed 17 Apr 2015.

41. Eurostat. Revision of the European Standard Population. Luxembourg: Office of the European Union; 2013.

42. Team RDC. R: A language and environment for statistical computing. Vienna: R Foundation for Statistical Computing; 2019. Available from: http:// www.R-project.org.

43. RJ G. A class of K-sample tests for comparing the cumulative incidence of a competing risk. Ann Stat. 1988:16:1141-54.

44. Kobayashi LC, Mateen FJ, Montana L, Wagner RG, Kahn K, Tollman SM, et al. Cognitive function and impairment in older, rural south African adults: evidence from "health and aging in Africa: a longitudinal study of an INDE PTH Community in Rural South Africa". Neuroepidemiology. 2019;52(1-2): 32-40.

45. Laws KR, Irvine K, Gale TM. Sex differences in cognitive impairment in Alzheimer's disease. World J Psychiatry. 2016;6(1):54-65.

46. Ward A, Arrighi HM, Michels S, Cedarbaum JM. Mild cognitive impairment: disparity of incidence and prevalence estimates. Alzheimers Dement. 2012 8(1):14-21.

47. Katsiardanis K, Diamantaras AA, Dessypris N, Michelakos T, Anastasiou A, Katsiardani KP, et al. Cognitive impairment and dietary habits among elders: the Velestino study. J Med Food. 2013;16(4):343-50.

48. Atti AR, Forlani C, De Ronchi D, Palmer K, Casadio P, Dalmonte E, et al. Cognitive impairment after age 60: clinical and social correlates in the Faenza project. J Alzheimers Dis. 2010:21(4):1325-34

49. Luck T, Luppa M, Briel S, Riedel-Heller SG. Incidence of mild cognitive impairment: a systematic review. Dement Geriatr Cogn Disord. 2010;29(2): 164-75.

50. Luck T, Luppa M, Briel S, Matschinger H, Konig HH, Bleich S, et al. Mild cognitive impairment: incidence and risk factors: results of the Leipzig longitudinal study of the aged. J Am Geriatr Soc. 2010;58(10):1903-10.

51. Hussin NM, Shahar S, Yahya HM, Din NC, Singh DKA, Omar MA. Incidence and predictors of mild cognitive impairment $(\mathrm{MCl})$ within a multi-ethnic Asian populace: a community-based longitudinal study. BMC Public Health. 2019;19(1):1159.

52. Mousavi-Nasab SM, Kormi-Nouri R, Sundstrom A, Nilsson LG. The effects of marital status on episodic and semantic memory in healthy middle-aged and old individuals. Scand J Psychol. 2012;53(1):1-8.

53. Bonsang $E$, Adam S, Perelman S. Does retirement affect cognitive functioning? J Health Econ. 2012:31(3):490-501.

54. FFMS. Retrato de Portugal: indicador População Residente: total por grandes grupos etários. Lisboa: PORDATA; 2020. Available from: https://www.pordata pt/DB/Portugal/Ambiente+de+Consulta/Tabela/5808044.

55. FFMS. Retrato de Portugal: indicador População residente com 65 e mais anos: por nível de escolaridade completo mais elevado. Lisboa: PORDATA; 2020. Available from: https://www.pordata.pt/DB/Portugal/Ambiente+de+ Consulta/Tabela/5808042.

\section{Publisher's Note}

Springer Nature remains neutral with regard to jurisdictional claims in published maps and institutional affiliations.

Ready to submit your research? Choose BMC and benefit from:

- fast, convenient online submission

- thorough peer review by experienced researchers in your field

- rapid publication on acceptance

- support for research data, including large and complex data types

- gold Open Access which fosters wider collaboration and increased citations

- maximum visibility for your research: over $100 \mathrm{M}$ website views per year

At $\mathrm{BMC}$, research is always in progress.

Learn more biomedcentral.com/submissions 